\title{
Erratum to: Advances in SPECT camera software and hardware: Currently available and new on the horizon
}

\author{
E. Gordon DePuey, MD
}

\section{ERRATUM TO: J NUCL CARDIOL 2012;19:551-81 \\ DOI 10.1007/S12350-012-9597-7}

Last line of page 556/first line of page 557: "Data Spectrum" should be replaced with "Spectrum Dynamics". doi:10.1007/s12350-012-9544-7.

Reprint requests: E. Gordon DePuey, MD, St. Luke's Hospital, Nuclear Medicine, New York, NY; edepuey@chpnet.org.

J Nucl Cardiol 2012;19:1085.

1071-3581/\$34.00

Copyright $(\subset 2012$ American Society of Nuclear Cardiology.

doi:10.1007/s12350-012-9597-7 